\title{
“The Veterans Project": Historiography in/as Performance
}

\section{Erika Hughes, University of Portsmouth}

“There's so much dancing in the desert because there's not another thing to do out there." Matthew

A young soldier wearing sand-colored fatigues, his sleeves rolled up to his elbows, shimmies and twerks in a homemade video projected onto a large screen in the Lyceum Theatre in Tempe, Arizona. Beneath the screen sit four veterans: three male, one female, all in their late twenties and early thirties, from the US Army, Navy, and Air Force. As the onscreen dancer turns to the side, spanking his imaginary dance partner under the hot desert sun, Matthew, a combat veteran seated onstage, continues his commentary: "That's the thing about combat—it's 99 percent boredom, 1 percent scared shitless."

This essay combines critical reflection with dramaturgical analysis to detail some of the questions that arose when working in applied ethnographic theatre with veterans of the US armed forces. In the aftermath of 9/11, theatre has grappled with ongoing armed conflicts through a number of recent projects and initiatives performed throughout the country, including The Telling Project (2008-present), Holding It Down: The Veterans' Dreams Project (2013), and Basetrack Live (2014). Each of these works has taken a different approach to performance (for example, historical dramatization, musical theatre, or documentary theatre) and has involved veterans in a number of different capacities (as collaborators, performers, consultants, or authors), but all share a fealty to the notion of a fixed, stable script. By contrast, "The Veterans Project" is an unscripted performance series that provides a live forum for veterans to share their stories with their communities. Now in 
its fifth year, this synthesis of oral and public history and performance is presented annually in a series of live events as part of the university-wide "Salute to Service" week coinciding with Veterans Day at Arizona State University (ASU), one of the largest universities in the United States. Each year, our production team works with veterans, many of whom are students, staff, or faculty from the ASU campuses throughout the Phoenix metropolitan area, to both create and document performances unique to their personal experiences. Through this project we have sought to transform performance into a consciously historiographical space. We use tools from the digital humanities to create work that comments on itself as it is being performed, simultaneously creating and disrupting narratives through structured improvisation and challenging audiences' notions of who serves and why.

I begin this essay with a consideration of some of the goals of embodied historiography from the perspective of a theatre historian and dramaturg, and discuss its application as dramaturgical form in "The Veterans Project." I then analyze performance and documented rehearsal examples from three of the six times that "The Veterans Project" was staged from 2013 to 2016 to ask to what extent the process of improvisational "truth-telling" through performance might serve to translate experience and transform dialogue, or conversely to reinforce stereotypes that perpetuate the military/ civilian divide. Each of the discussed performances featured male and female cis-gendered veterans onstage, and our most recent performance also featured one transgendered man. I am choosing to focus on female veterans because of the frequency with which their gender was itself an issue in the stories they told about their service. I found this factor to be particularly significant, given that while nearly a fourth of the male population of the country are veterans of the armed forces, only 2 percent of all US women are veterans (Newport). My analysis is guided in part by the work of Michael Frisch, whose 1990 A Shared Authority posed major challenges to the fields of oral and public history through its reconsideration of the "very processes of 
engagement, in the altered relationship between historian and 'source,' between scholarship and public discourse, and between dominant cultural forms, assumptions, and institutions and the alternatives that practitioners of these methods so often hope to empower" (xiv). As it is enacted onstage, embodied historiography uses the space of the theatre in an attempt to meet Frisch's challenge; in its blurring of the lines between dominant and alternative narratives, performer and subject, I posit that "The Veterans Project" upends the traditional hierarchy between historian and source.

\section{Embodied Historiography}

"The Veterans Project" is the result of a collaboration between myself and Boyd Branch, a digital media designer and technologist for live performance. We understand embodied historiography to be an evolving fusion of methodologies from oral and public history, applied theatre, postdramatic theatre, and new media technologies that we developed specifically within this project. So far, our work in embodied historiography has been largely focused on veterans of the US military, although we have also worked with female university students in Pakistan and teaching artists in New York City. Individually, I am writing this analysis from the perspective of a humanities-grounded collaborator with a theatre technologist and performers who represent how they remember and understand their own lived experiences through the subjective genre of storytelling. The performers share unscripted individual stories with one another that are at turns interrupted or embellished by various media onscreen; the end result is something of a curated conversation. Our initial hypothesis was that this unique fusion of methodologies would beget a kind of "embodied historiography" in which the performers are themselves recognized as historical documents who would, through the act of performing, "expose our subjective processing of memory and historical events through the live layering of multiple perspectives" (Branch and Hughes 108). 
"The Veterans Project" draws its aesthetic inspiration from postdramatic theatrical techniques, which harness elements traditionally considered less important to an Aristotelian framework—namely, spectacle, sound, and diction. As Hans-Thies Lehmann wrote in Postdramatic Theatre, "[t]he mode of perception is shifting: a simultaneous and multiperspectival form of perceiving is replacing the linear-subjective" (16). As such, we seek to move beyond the genre of documentary theatre, which is limited by its use of actors as performers and the often heavy editorial hand that guides and organizes linear historical data through both devising and directing. By placing the performers in the role of "documents," we hope that their accounts can be read by the audience as self-contained truths of the moment that also generate a more comprehensive truth born from their collective accounts. In this regard we are influenced by "polydrama," a genre that, according to Israeli playwright and director Joshua Sobol,

doesn't attribute much importance to a storyline, and disregards the storyline as an important fact. A Polydrama supposes that truth resides in a comprehensive structure of the entire story. And it does not matter in what way you are progressing or surfing through the story. First of all: truth resides in every single moment there. So every episode is as important as the entire story. Every episode is a world in itself, and the order of the episodes is not important. (n.p.)

Watching or reading a work of polydrama is reminiscent of the choose-your-own-adventure genre that presented its audience with a set of possibilities that could be strung together in a number of different configurations, with each different configuration affecting not only plot outcomes, but also each audience member's relationship to a text. However, whereas polydrama traditionally asks the audience member to physically move through the performance space, following certain actors down certain paths, embodied historiography 
changes the physically fixed performance space through the use of a wide range of visual and auditory media - in this case, about the military.

Our ever-growing database of videos includes clips from classic Hollywood war movies, homemade videos found on YouTube and Vimeo by soldiers and civilians alike, and television commercials for military recruitment from every branch and from nearly every decade since the 1950s. Most videos are edited down to somewhere between thirty seconds to a minute in duration, then are selected at random during the performance by a media system that was created specifically for this performance series. The media countertext serves as a conduit for conversation and storytelling: because of the randomization of selection, the veterans onstage do not know which videos will be played during the performance, and they watch the clips together with the audience, often for the first time, before offering commentary from their individual perspectives. Each performer has individual access to basic video controls onstage (through a tablet device) and all are encouraged to pause, fast-forward, skip, or repeat videos during the performance.

From an ethical standpoint, the production team does not override the veterans' choices. We encourage them to express their displeasure at the inclusion of certain videos with the audience and production team during the performance. Indeed, if they ask us to not include a topic or specific video, it is our ethical responsibility to comply — no questions asked. However, sometimes the performers with whom we have worked have asked that the choice be made available to them onstage, so that they might decide in the moment what they would like to share (or not) with one another and with the community in the audience. This makes for a very powerful aesthetic choice; in one rehearsal immediately preceding a performance a female veteran had described mistreatment by a senior male colleague in great and moving detail. However, during the performance, when a video about harassment appeared onscreen, the veteran said to the audience, her fellow performers, and the 
production team, "No, I don't want to talk about that," coupled with the physical gesture of pressing a button to advance the video. The framework that allowed the performer to make this staging choice, which was done entirely in the moment, created a powerful aesthetic of agency in the shadow of personal trauma. This act of rendering as present the absence of her testimony made the choice to speak what she did, when she did, all the more powerful.

"The Veterans Project" has thus far been performed six times over the past four years throughout Arizona, each time with a different group of veterans. Venues have included a 160-seat proscenium on ASU's Tempe campus, an art gallery in downtown Phoenix, the Arizona State Museum in Tucson (in collaboration with the University of Arizona), and Filmbar, an independent art-house cinema in Phoenix. In these performances, veterans shared a range of personal accounts from US wars in Vietnam, Iraq, and Afghanistan to peacetime posts stateside, at sea, and on American bases in Germany and Japan. Ranging in age from 22 to 70 , they come from a variety of cultural, ethnic, and class backgrounds and served in numerous positions in the armed forces, including paratrooper, military police, CBRN (chemical, biological, radiological, nuclear) specialist, helicopter captain, intelligence officer, recruiter, and infantry person. The majority of veterans featured in our performances are currently ASU students, alumni, faculty, or employees. Their post-graduation tracks have included teaching, firefighting, and running for the Arizona state senate.

Each performance of "The Veterans Project" is unique. Past iterations have showcased discussions that probed memories of loss and death, friendly competitions and infidelities among soldiers, sexual violence, sexual relations with local civilian populations, training activities, trading MREs (meals ready to eat), and the difficulties of having certain conversations with those without military experience. In presenting these episodes onstage to civilian and military community members, "The Veterans Project" aims to place the audience in the role of historian. As theatre historian Freddie Rokem notes in his Performing History, 
"[o]ne of the common features of theatre and historiography—at least the history of mentality - is that in different ways both strive to expose or disclose something in the public sphere that has previously been perceived as private" (100). Yet, while Rokem and others have been primarily concerned with performance that takes as its primary subject matter the historical event as recreated by actors in role, this project seeks to transform the performative space into one that is inherently historiographical — that is, rendering transparent the metaprocesses of creating narrative through performance.

The military veterans who have performed in this project were active participants in the histories that they are attempting to share and convey to the audience; as such, they are both witnesses to and documents of the historical event. By acknowledging this unique status, we aim to investigate how narratives are changed, disrupted, altered, and otherwise affected when performance techniques are used as a means through which to gather oral history. According to the Oral History Association, "[o]ral history refers both to a method of recording and preserving oral testimony and to the product of that process. It begins with an audio or video recording of a first-person account made by an interviewer with an interviewee (also referred to as narrator), both of whom have the conscious intention of creating a permanent record to contribute to an understanding of the past" (n.p.). "The Veterans Project" seeks to act as both a site of community engagement with the living histories of soldiers embedded in civilian life, and as a repository for this history. In the following section I analyze content from four previous performances, examining the ways in which this format serves to reinforce and/or reject dominant narratives about what it means to be a (female) veteran.

\section{In Their Own Words: "The Veterans Project"}

\section{Joanna}


"It's probably one of the most traumatic experiences of my life, ... and also one of the most joyous and proud organizations." - Joanna

In a recruiting commercial for the US Army during the 1980s, two male soldiers are seen in the cockpit of an aircraft. "Low fuel, heavy weather," one says into his headpiece. The screen cuts to a female soldier at air traffic control, guiding them in landing. A male voiceover says that "[w]ith a fog-bound helicopter hanging on your every word, it doesn't matter if you're a man or a woman — only that you're good." "Thanks for your help," we then hear the male pilot saying to the female soldier. "Roger that," she replies, grinning. The music swells "Be all that you can be ...," but before the song finishes Karen, a female veteran seated onstage, stops the video from projecting on the large screen behind her. "As a member of the US Army, I want to apologize-for that commercial, and every other one the army has ever produced," she says. The line gets laughter from both the audience and her fellow performers onstage. "Oh, it was funny because I got — they signed me up for com," laughs Joanna, a female veteran of the marine corps seated next to Karen. "And they said, oh, communications, it's like broadcasting, like journalism." Gesturing to the screen and the image of the female soldier in the commercial, she continued: "even that looks super amazing, because she's got the headgear on, and a switchboard, but no, I had to carry some gear, you know, from, I don't know, 1942 on my back, with a large antenna . . . it says, shoot me first, please!"

This moment from the November 2014 production, which featured four veterans, two male and two female (one each from the navy, army, air force, and marine corps), served to establish a kind of rejection of military-produced (and -sanctioned) imagery. Joanna's and Karen's reactions to this commercial pushed back against the military's mediated depictions of female soldiers by poking fun at the ad's perceived earnestness, then offered the complexities of their own lived experiences as retorts. This led into a general conversation 
among all the veterans onstage about the dissonance between military advertising and military life. When Joanna, who eventually became a marine recruiter, went on to share how she approached potential recruits, the other veterans took the opportunity to poke fun at the iconography of marine commercials. "You didn't tell them that they were going to go out and slay dragons? I mean the army is 'be all you can be,' but the marine corps, you get to climb these high cliffs," quipped Steve, a former naval pilot and officer.

The discussion of this duality_preconception and reality — led Joanna to reflect on the dual experiences of pain and pride that she derived from her service: "Being a marine is . . it's probably one of the most traumatic experiences of my life, becoming a marine, and also one of the most joyous and proud organizations, just to be a part of it." The specifics that Joanna shared during the rest of the performance went on to include both awkward exchanges with soldiers from other branches of the armed forces and the strong bonds that she formed with many of her fellow female marines. The military experience is not one that is universally understood, even by those who have lived it. The dialogic approach to collectively sharing these stories facilitated the veterans' pushing beyond preconceived narratives together, thus allowing space for individual critical reflection. Publicly rejecting the military's equivocating depiction of female soldiers in one of its old ads led to a wholesale rejection of military advertising, and, as if to fill the void created by this rejection, a subsequent sharing of deeply personal truths.

Karen

"So no shit, there I was." —Karen

During rehearsals for the first performance of "The Veterans Project" in November 2013, the veterans told the production team about "no shit, there I was" stories: a genre of military story akin to fishing tall tales that might be a bit exaggerated, because the first 
priority is telling a good story though not necessarily a true one. We thought that this would make a fascinating addition to the stories being told onstage, because it would ask the audience to reflect on the reliability of memory and the relationship of storyteller to truth; the opening line_-"no shit, there I was"- - signifies a level of exaggeration and craft to the story. Our team recorded the veterans telling their favorite "no shit, there I was" stories on video to add to our media database, and Karen, a Gulf War veteran who appeared in three of our performances, chose a funny story that played with the tension between US gender norms and military service:1 "So no shit, there I was. Biggest camel spider I ever saw crawling out of my boots and nothing to kill it with but a can of Aquanet from the girl who came from New York. And I'm not kidding—a single can of Aquanet will kill a camel spider.”

Her stories frequently used humor to reflect an acute awareness of the complexities of gender dynamics in the service. The humor in this particular story relies upon the incongruity between expected gender norms, as she uses a classic beautician's tool (Aquanet hairspray) to kill a dangerouslooking (although largely harmless) creature somewhere on the spectrum between a spider and a scorpion. The "girl who came from New York" reference also plays on the ways in which soldiers sometimes represent regional differences and rivalries. Yet, Karen's story also reflects the way in which many military stories by female soldiers also convey a sense of working and living in a highly maledominated sphere. As of 2010, men comprised approximately 85 percent of active-duty members of the US armed forces. 2 In its reappropriation of hairspray into a weapon of death, Karen's story confronts the reality, and absurdity, of this statistic.

\section{Shantelle}

"But how many times have you had to use push-ups and sit-ups in combat?" - Shantelle 
In what was easily the most heated exchange on the stage of "The Veterans Project," the entire cast of the November 2015 production discussed the rights of women in the military to hold the same jobs as men (fig. 1). At the time of the performance, women were eligible to serve in 90 percent of military jobs, but it was not until December 2015-less than one month after the performance - that Secretary of Defense Ash Carter announced that women would be eligible for all jobs in the military beginning in January 2016. This cast, comprised of three men and one woman, was the youngest one we have had; it consisted of two army veterans, and one each from the navy and air force. Three of them were in favor of making all jobs available to women; however, one disagreed, citing his anxieties about female soldiers who were not held to the same physicalaptitude standards as their male counterparts. While all three pushed back against this argument, only Shantelle, a female naval veteran, understood the double standards of military requirements from the inside. She replied, "nobody can argue [against] that in this very male-dominated culture, it's really, really difficult to squeeze in as a female — even when you are outperforming all of your peers, you've gotta work harder, you've gotta stay later, just to not be seen as a slacker." And indeed, nobody onstage did argue against this point, giving the distinct impression that not one of the three men seated alongside her could. Shantelle went on to challenge the metrics used by the military to define and determine equality, asking the men with whom she shared the stage, “[b]ut how many times have you had to use push-ups and sit-ups in combat?" Her probing illustrated how training and successful implementation cannot be merely measured in target numbers, particularly when the target numbers privilege one set of aptitudes over another.

Shantelle quite literally had the last word in the show, as we asked her to close the performance and to invite the audience to join the cast and crew for an informal talkback at a nearby bar. This began as an idea from the first cast of veterans in the project, and has since 
turned into something of a tradition, offering the individuals onstage and audience members the chance to engage in conversation. Watching Shantelle bring the performance to an end not long after this exchange served to invert stereotypical notions of women not occupying positions of leadership. Yet, reflecting back on her words has left me questioning the very metrics that shape this series of performances.

\section{Concluding Questions}

As I review these three examples of oral histories shared by educated women who are veterans of three different military branches, I cannot help but wonder: Does this performance series perform a resistance against normative understandings of gender within the military, or a reinforcement of them? How much do these structures reify and replicate themselves in conversation, even as we attempt to disrupt them discursively and historiographically? The examples given here are not unique in their referencing of gender dynamics, in comparison with the other moments in which female veterans shared their stories. I believe that our attempts at dramaturgical disruption have made significant gains in opening up spaces to record voices that are statistically underrepresented. Yet, I also wonder what other metrics, sources, and dramaturgical interventions can be made to further disrupt preexisting power dynamics. Our performers are responding to prerecorded media that is borne of and frequently establishes a binary understanding about both gender and a woman's relationship to service in the armed forces. To what extent can performances of "The Veterans Project" address the biases already embedded in the countertext? What additional sources might we include that value these veterans' experiences on their own merits?

In A Shared Authority Frisch acknowledges that "[i]f oral historians need to understand that their method involves much more than the extraction of knowledge from human history mines, public historians need to realize that their method can do much more 
than merely redistribute such knowledge." His call was for a forum that would "promote a more democratized and widely shared historical consciousness, consequently encouraging broader participation in debates about history, debates that will be informed by a more deeply representative range of experiences, perspectives, and values" (xxi). "The Veterans Project" demonstrates the efficacy of using embodied historiography as a dramaturgical form that can highlight multiple perspectives, encourage debate, and reject teleology in both genre and content. As of this writing, Shantelle and Karen are both still involved in "The Veterans Project," but now as a part of our production team. Additionally, as a means of introducing a new source of intervention, Shantelle and another project alumni contributed original music to the November 2016 performance, and in so doing provided additional support to the veterans. By filling the space with sound, the improvised music served not only to score the performers' stories, but to support them in moments of silence and difficulty. Our collective hope is that as we continue this collaboration together, our form will also continue to evolve, both with our society's ever-transforming relationship to technology and with the individuals that take the stage in each performance. How might the inclusion of, for example, audienceled interactions further the process of intervention as it relates to subverting dominant narrative structures? We hope that future performances will continue to shed light on these questions, even as they stimulate new questions about how we understand history and its diverse sources.

Erika Hughes is a senior lecturer in drama and performance at the University of Portsmouth. Her written work has appeared in Performance Research, Journal of European Studies, Youth Theatre Journal, and a number of edited volumes. Her work as a director has been seen on stages in the United States, Israel, Germany, and Pakistan. 


\section{Notes}

1. So as to give her the experience of performing onstage on campus, we invited Karen to join the next group of veterans in November 2014. She also joined two other veterans from a prior performance in May 2014 when the show toured to Tucson.

2. See Center for Naval Analyses (CNA), Population Representation in the Military Services: Fiscal Year 2010 Summary Report (2010).

\section{Works Cited}

Branch, Boyd, and Erika Hughes. "Embodied Historiography: Rupture as the Performance of History." Performance Research 19.6 (2014): 108-15. Print

Carter, Ash. "Memorandum: Implementation Guidance for the Full Integration of Women in the Armed Forces." 3 Dec. 2015. Web. 5 Aug. 2017.

Center for Naval Analyses (CNA). Population Representation in the Military Services: Fiscal Year 2010 Summary Report. Arlington, VA: CAN, 2010. Print.

Frisch, Michael. A Shared Authority: Essays on the Craft and Meaning of Oral and Public History. Albany: State U of New York P, 1990. Print.

Lehmann, Hans-Thies. Postdramatic Theatre. Trans. Karen Jürs-Munby. Abingdon, UK: Routledge, 2006. Print.

Newport, Frank. “In U.S., 24\% of Men, 2\% of Women Are Veterans.” Gallup. 12 Nov. 2012. Web. 5 Aug. 2017.

Oral History Association. "Principles and Best Practices for Oral History." 2009. Web. 5 Aug. 2017. 
Rokem, Freddie. Performing History. Iowa City: U of Iowa P, 2000. Print.

Sobol, Joshua. “What Is a Polydrama?” Alma: Press Corner. N.d. Web. 5 Aug. 2017.

“The Veterans Project.” Performances, Lyceum Theatre, Tempe, Arizona. November 14, 2013, November 13, 2014, and November 12, 2015 